Research Article

\title{
Comprehensive In Silico Screening of the Antiviral Potentialities of a New Humulene Glucoside from Asteriscus hierochunticus against SARS-CoV-2
}

\author{
Vincent O. Imieje $\mathbb{D}^{1,},{ }^{1,2}$ Ahmed A. Zaki ${ }^{\left(\mathbb{D},{ }^{3,4}\right.}$ Ahmed M. Metwaly ${ }^{\mathbb{D}},{ }^{5}$ Ahmad E. Mostafa ${ }^{(D)}{ }^{5}$ \\ Eslam B. Elkaeed $\left(\mathbb{D},{ }^{6}\right.$ and Abiodun Falodun $\mathbb{D D}^{1}$ \\ ${ }^{1}$ Department of Pharmaceutical Chemistry, Faculty of Pharmacy, University of Benin, Benin City 300001, Nigeria \\ ${ }^{2}$ National Centre for Natural Products Research, Institute of Pharmaceutical Sciences, School of Pharmacy, \\ University of Mississippi, Oxford, MS 38677, USA \\ ${ }^{3}$ Pharmacognosy Department, Faculty of Pharmacy, Mansoura University, Mansoura 35516, Egypt \\ ${ }^{4}$ Department of Pharmacognosy, Faculty of Pharmacy, Horus University-Egypt, New Damietta 34518, Egypt \\ ${ }^{5}$ Pharmacognosy and Medicinal Plants Department, Faculty of Pharmacy (Boys), Al-Azhar University, Cairo 11884, Egypt \\ ${ }^{6}$ Department of Pharmaceutical Sciences, College of Pharmacy, AlMaarefa University, Ad Diriyah 13713, Riyadh, Saudi Arabia
}

Correspondence should be addressed to Vincent O. Imieje; vincent.imieje@uniben.edu

Received 26 February 2021; Revised 26 May 2021; Accepted 28 July 2021; Published 9 August 2021

Academic Editor: Wagdy Eldehna

Copyright (c) 2021 Vincent O. Imieje et al. This is an open access article distributed under the Creative Commons Attribution License, which permits unrestricted use, distribution, and reproduction in any medium, provided the original work is properly cited.

\begin{abstract}
Chromatographic fractionation of the methanolic extract of Asteriscus hierochunticus whole plant led to the identification of a new humulene glucoside (1). The chemical structure of the isolated compound was elucidated by IR, 1D, 2D NMR, and HRESIMS data analysis to be (-)-(2Z,6E,9E) $8 \alpha$-hydroxy-2,6,9-humulatrien-1(12)-olide. In this study, we report the in silico binding affinities of 1 against four different SARS-CoV-2 proteins (COVID-19 main protease (PDB ID: 6lu7), nonstructural protein (PDB ID: 6W4H), RNA-dependent RNA polymerase (PDB ID: 7BV2), and SARS-CoV-2 helicase (PDB ID: 5RMM)). The isolated compound showed excellent binding affinity values $(\Delta \mathrm{G})$ of $-21.65,-20.05,-28.93$, and $-21.73 \mathrm{kcal} / \mathrm{mol}$, respectively, against the target proteins compared to the cocrystallized ligands that exhibited $\Delta \mathrm{G}$ values of $-23.75,-17.65,-23.57$, and $-15.30 \mathrm{kcal} / \mathrm{mol}$, respectively. Further in silico investigations of the isolated compound (1) for its ADMET and toxicity profiles revealed excellent drug likeliness. On the other hand, the results obtained from in vitro antitrypanosomal, antileishmanial, and antimalarial activities of (1) were not promising.
\end{abstract}

\section{Introduction}

The world witnessed the emergence of SARS-CoV-2 in the later part of 2019 from the Wuhan district of China, leading to millions of deaths worldwide and a total lockdown of most economies with attendants' socioeconomic impact [1]. By November 2020, more than 33 million humans have been infected and more than other 1.3 million have died all over the world according to the WHO [2]. Unfortunately, there is no available treatment for COVID-19. The symptomatic treatment based on anti-inflammatory agents such as dexamethasone, some research drugs, and ventilators (oxygen perfusion) in severe cases is currently used for treatment of affected persons [3]. Coronaviruses generally have been linked with debilitating diseases that have previously affected a wide range of the population, Middle East Respiratory Syndrome (MERS-CoV) and Severe Acute Syndrome (SARS-CoV) that appeared in $2003[4,5]$.

Humans always relied on the nature as the major curative of diseases [6,7]. Increased use of natural products in the last few decades has been witnessed for various purposes, especially as a source for primary healthcare to most of the 
world population [8]. Natural products are not only used as a major source of new bioactive molecules for managing of several diseases but also as a starting material in the synthesis of new potent pharmacological compounds [8]. Plants and microbes could be a source for the effective natural products [9-13]. The efficacy of natural products as curatives is enhanced due to the presence of varied types of compounds as saponins [14, 15], alkaloids [16], pyrones [17], isochromenes [18], flavonoids [19, 20], diterpenes [21], and sesquiterpenes lactones [22, 23].

Asteriscus hierochunticus (Michon) A. Wiklund is a widely distributed shrub that belongs to family Asteraceae and found in tropical regions, including Asia, the Americas, Africa, the Middle East and the Mediterranean region, Europe, and some islands in the Pacific and Atlantic oceans [24]. The genus Asteriscus is used in folk medicine for treatment and managing of different disease conditions, such as inflammations, fevers, cancers, stomach aches, bronchitis, hemorrhoids, and other disorders [25]. Phytochemical and pharmacological investigations on other members of the genus have been reported and resulted in the isolation of bioactive secondary metabolites such as sesquiterpenes, diterpenes, and phenolics [26], but for A. hierochunticus, there was no enough phytochemical investigation. The isolation and characterization of bioactive humulene sesquiterpenes lactones, such as asteriscunolides A-D [27, 28], steriscanolide, and aquatolide [29], from some species of genus Asteriscus had been reported. These isolated compounds have been screened for their antitrypanocidal, cytotoxic, antidiabetic, antiprotozoal, and antiparasitic activities [30-33].

The current study investigates the phytochemistry of A. hierochunticus whole plant through chromatographic isolation and in silico anti-COVID-19 screening for the isolated compounds.

\section{Materials and Methods}

2.1. General. It is detailed in the supporting information.

2.2. Plant Material. It is detailed in the supporting information.

2.3. Extraction and Isolation. They are detailed in the supporting information.

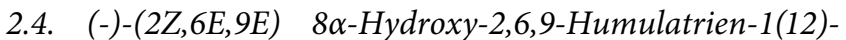
Olide (1). It is detailed in the supporting information.

\subsection{In Silico Studies}

2.5.1. Conformational Search for Humulene-Glucoside 1. Conformational search for humulene-glucoside (1) was carried out using the LowModeMD Search protocol using MOE2014 [34]. See the supporting information for more details.
2.5.2. Molecular Docking. Molecular Operating Environment (MOE) was used for the docking analysis, see the supporting information.

2.5.3. ADMET. Discovery studio 4.0 was used [35], see the supporting information.

2.5.4. In Silico Toxicity. Discovery studio 4.0 was used [36], see the supporting information.

2.6. Antileishmanial Assay. Humulene-glucoside (1) was evaluated against Leishmania donovani promastigote, Leishmania donovani axenic amastigote, and Leishmania donovani intracellular amastigote using Alamar Blue colorimetric assay [37], see the supporting information.

2.7. In Vitro Macrophage Amastigote Assay. This was performed according to the parasite-rescue and transformation assay described in $[37,38]$, see the supporting information.

2.8. Antitrypanosomal Assay. This assay was carried out according to a method previously described [39], see the supporting information.

2.9. Cytotoxicity Assay. The cytotoxicity of humulene-glucoside (1) was also tested against transformed human monocytic (THP1) cells [38], see the supporting information.

2.10. Antimalarial Assay. The antiplasmodial activity of humulene-glucoside (1) was determined using a colorimetric assay that measures the parasite's lactate dehydrogenase (pLDH) activity [40], see the supporting information.

\section{Results}

3.1. Isolation of Humulene-Glucoside (1) and Structure Elucidation. The phytochemical investigation of A. hierochunticus extract resulted in the purification of a new humulene-glucoside (1) (Figure 1).

Humulene-glucoside (1) was isolated as white needles with $[\alpha]^{25} 78.6$ (c $0.1, \mathrm{CH}_{3} \mathrm{OH}$ ). Its molecular formula, $\mathrm{C}_{21} \mathrm{H}_{30} \mathrm{O}_{8}$, was determined based on the molecular ion peak $[\mathrm{M}+\mathrm{Na}]^{+}$at $\mathrm{m} / \mathrm{z} 433.1783$ (calc. 433.1838) in the HRESIMS. The IR spectrum of $\mathbf{1}$ exhibited the absorption bands at 3391 $(\mathrm{OH})$ and $1748(\mathrm{C}=\mathrm{O})$. The ${ }^{1} \mathrm{H}$ NMR spectrum exhibited three singlet signals due to three tertiary methyls $\left(\delta_{\mathrm{H}}, 1.48(\mathrm{~s}\right.$, $\left.3 \mathrm{H}, \mathrm{H}_{3}-13\right), 1.17$ (s, 3H, $\left.\mathrm{H}_{3}-14\right)$, and 1.06 (s, 3H, $\left.\mathrm{H}_{3}-15\right)$ ). Four olefinic protons $\left(\delta_{\mathrm{H}} 5.07\right.$ (br s, H-6), 5.58 (dd, $J=16.1$, $8.1 \mathrm{~Hz}, \mathrm{H}-9), 5.22$ (d, $J=16.0 \mathrm{~Hz}, \mathrm{H}-10)$, and $7.27(\mathrm{~s}))$ and the signals attributed to six oxygenated methine protons $\left(\delta_{\mathrm{H}} 2.96\right.$ (overlapped, H-2 ${ }^{\prime}$ ), $3.09\left(\mathrm{t}, J=8.9 \mathrm{~Hz}, \mathrm{H}-3^{\prime}\right), 3.02(\mathrm{td}, J=8.9$, $\left.3.0 \mathrm{~Hz}, \mathrm{H}-4^{\prime}\right), 2.95$ (m, H-5 $\left.{ }^{\prime}\right), 4.79$ (d, $\left.J=8.1 \mathrm{~Hz}, \mathrm{H}-8\right)$, and $4.62(\mathrm{~s}, \mathrm{H}-1))$, one anomeric proton $) \delta_{\mathrm{H}} 3.86(\mathrm{~d}, J=7.8 \mathrm{~Hz}$, $\left.\left.\mathrm{H}-1^{\prime}\right)\right)$, and one oxygenated methylene $\left(\delta_{\mathrm{H}} 3.40(\mathrm{dt}, J=11.8\right.$, $\left.5.7 \mathrm{~Hz}, \mathrm{H}-6^{\prime} \mathrm{a}\right)$ and $3.63\left(\mathrm{ddd}, J=11.8,6.1,2.1 \mathrm{~Hz}, \mathrm{H}-6^{\prime} \mathrm{b}\right)$ ). 


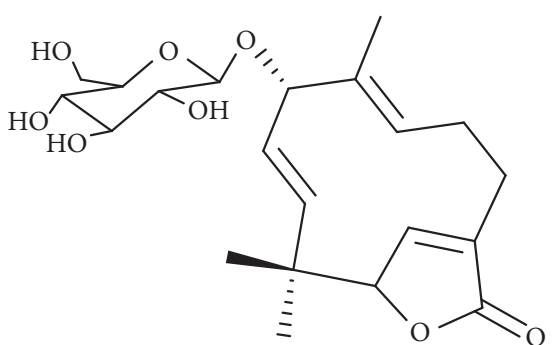

Figure 1: Chemical structure of humulene-glucoside (1).

The ${ }^{13} \mathrm{C}$ NMR and DEPT-135 spectra showed the presence of $\gamma$-lactone, together with six olefinic carbons, three methyls, two methylenes, two methines, and one quaternary carbon, as well as one sugar moiety. The ${ }^{13} \mathrm{C}$ and ${ }^{1} \mathrm{H}$ data of compound (1) are shown in Table 1 . The analysis of ${ }^{1} \mathrm{H},{ }^{13} \mathrm{C}$, and DEPT-135 NMR spectra of (1) revealed the presence of sesquiterpene lactone of humulene skeleton in the glycoside form. The protons' connectivities were confirmed by both HMQC and HMBC spectrum, and the humulanolide structure was established (Figure 2). By considering the coupling constant between $(\mathrm{C} 9=\mathrm{C} 10)\left(J_{9-10}=16.1 \mathrm{~Hz}\right)$, its stereochemistry was determined to be $\mathrm{E}$, as well as the geometry of double bond between (C6=C7) [41, 42]. By comparing the NMR data, with the reported one, it revealed the structure of asteriscunolide D [28], except for the absence of a carbonyl signal at C-8 which was replaced by an oxygenated methine at $\delta_{\mathrm{C}} 83.9$, attached for a sugar moiety. The $\alpha$-orientation of the hydroxy group at C- 8 was deduced from the chemical shift and coupling constant value of $\mathrm{H}-8$ [43]. Based on the NMR data and comparison with an authentic sample after hydrolysis, the sugar moiety was concluded to be $\beta$-D-glucose [44]. The correlations of $\mathrm{H}-1^{\prime}$ $\left(\delta_{\mathrm{H}} 3.86\right)$ with $\mathrm{C}-8\left(\delta_{\mathrm{C}} 83.9\right)$ and $\mathrm{H}-8\left(\delta_{\mathrm{H}} 4.79\right)$ with the anomeric carbon $\left(\delta_{\mathrm{C}} 99.9\right)$ in the HMBC spectrum revealed the sugar connection at C-8 (Figure 2). The structure of $\mathbf{1}$ was established to be (-)-(2Z,6E,9E) $8 \alpha$-hydroxy-2,6,9humulatrien-1(12)-olide.

\subsection{In Silico Studies}

3.2.1. Conformational Search for Humulene-Glucoside (1). In this work, conformational search for humulene-glucoside (1) was carried out using the LowModeMD protocol. The best conformer was with a potential energy (E) of $75.48 \mathrm{kcal} /$ mol. The strain energy of this conformer relative to the lowest energy conformation with the same stereochemistry configuration (dE) was $0.00 \mathrm{kcal} / \mathrm{mol}$. Besides, the integer encoding stereochemistry configuration of such conformer (CHI) was equal 1 . The radius of gyration of this conformer (RGYR) was 4.09. It was found that the globularity of the conformation (Glob) was 0.24 and the eccentricity of the conformation (Ecc) was 0.89 (Table 2 and Figure 3).

3.2.2. Molecular Docking. The main protease $\left(\mathrm{M}^{\mathrm{pro}}\right)$ is a vital chymotrypsin-like cysteine protease that belongs to the nonstructural type and plays a crucial role in the replication
TABle 1: ${ }^{13} \mathrm{C}$ and ${ }^{1} \mathrm{H}$ NMR data for humulene-glucoside (1) (DMSO- $d_{6}$, at 125 and $500 \mathrm{MHz}$, respectively).

\begin{tabular}{|c|c|c|}
\hline $\mathrm{C}$ & $\delta_{\mathrm{C}}$ & $\delta_{\mathrm{H}}$ \\
\hline 1 & 87.5 & $4.62(\mathrm{~s})$ \\
\hline 2 & 149.4 & $7.27(\mathrm{~s})$ \\
\hline 3 & 132.6 & - \\
\hline 4 & 24.9 & $2.38, \mathrm{dd}(J=5.7,10.4 \mathrm{~Hz})$ \\
\hline 5 & 22.8 & 2.05 , br. d $(J=12.8 \mathrm{~Hz}) 2.66$, tdd $(12.8,10.8,7.1 \mathrm{~Hz})$ \\
\hline 6 & 126.0 & 5.07 (br. s) \\
\hline 7 & 140.9 & - \\
\hline 8 & 83.9 & $4.79, d(J=8.1 \mathrm{~Hz})$ \\
\hline 9 & 131.6 & $5.58, \mathrm{dd}(J=16.1,8.1 \mathrm{~Hz})$ \\
\hline 10 & 134.9 & $5.22, d(J=16.1 \mathrm{~Hz})$ \\
\hline 11 & 40.3 & - \\
\hline 12 & 172.6 & - \\
\hline 13 & 11.4 & $1.48(\mathrm{~s})$ \\
\hline 14 & 25.6 & $1.17(\mathrm{~s})$ \\
\hline 15 & 21.4 & $1.06(\mathrm{~s})$ \\
\hline $1^{\prime}$ & 99.9 & $3.86, d(J=7.8 \mathrm{~Hz})$ \\
\hline $2^{\prime}$ & 73.4 & 2.96, overlapped \\
\hline $3^{\prime}$ & 76.9 & $3.09, t(J=8.9 \mathrm{~Hz})$ \\
\hline $4^{\prime}$ & 70.2 & $3.02, \mathrm{td}(J=8.9,3.0 \mathrm{~Hz}) \mathrm{a}$ \\
\hline $5^{\prime}$ & 77.1 & $2.95(\mathrm{~m})$ \\
\hline $6^{\prime}$ & 61.2 & $\begin{array}{l}3.40, \mathrm{dt}(J=11.8,5.7 \mathrm{~Hz}) \mathrm{a} 3.63, \mathrm{ddd}(J=11.8,6.1, \\
2.1 \mathrm{~Hz}) \mathrm{a}\end{array}$ \\
\hline
\end{tabular}

${ }^{\mathrm{a} C o u p l i n g}$ with a hydroxyl proton too.

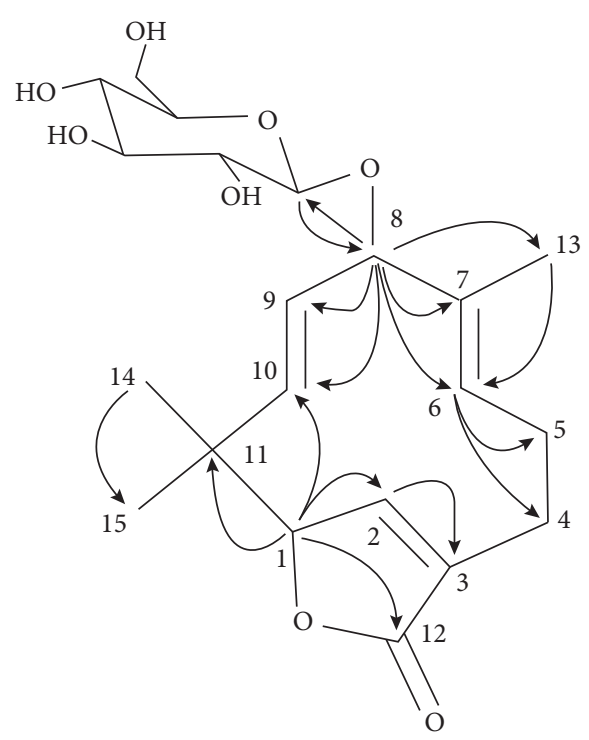

FIGURE 2: The key HMBC correlations of humulene-glucoside (1).

TABLE 2: The generated descriptors of the best energetic conformer for humulene-glucoside (1).

\begin{tabular}{lcccccc}
\hline Comp. & E & dE & CHI & RGYR & Glob & Ecc \\
\hline $\mathbf{1}$ & 75.48 & 0.00 & 1.00 & 4.09 & 0.24 & 0.89 \\
\hline
\end{tabular}

process of coronavirus. It releases the 16 nonstructural proteins (NSPs 1-16) via cleavage of the C-terminal end of the two polyproteins (PP1a and PP1ab) [45, 46]. The nonstructural protein (NSP10) is a vital cofactor for activation of the SARS-CoV replicative enzyme (replicase) [47]. 


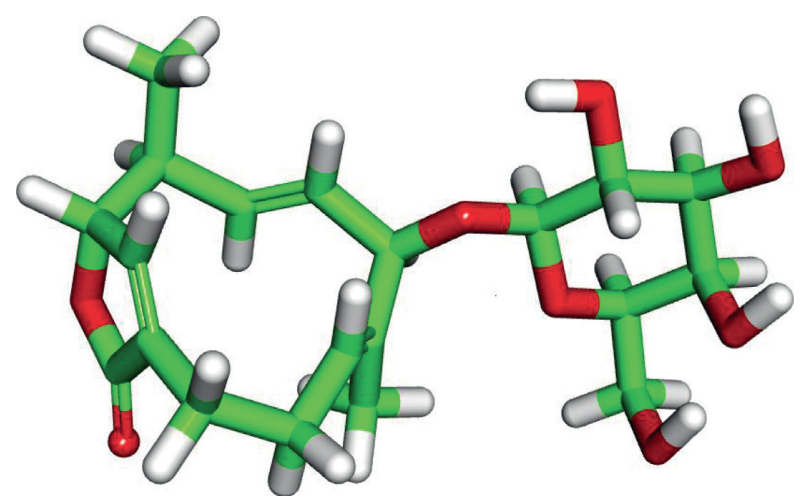

FIGURE 3: The configuration of the best generated conformer for humulene-glucoside (1).

RNA-dependent RNA polymerase or RNA replicase is the enzyme that is responsible for the replication process of RNA through catalyzing the synthesis of the RNA template complementary from the RNA strand [48]. Helicases are a group of enzymes that have the potentiality to separate double-stranded DNA or RNA. Helicase enzyme is very essential for the process of RNA replication and repair [49].

In the present work, the binding potential of humuleneglucoside (1) against four SARS-CoV-2 proteins has been investigated using the Molecular Operating Environment (MOE) [50-53]. The selected SARS-CoV-2 proteins are (i) COVID-19 main protease (M $\mathrm{M}^{\text {pro }}$ ) (PDB ID: 6lu7, resolution: $2.16 \AA$ ), (ii) nonstructural protein (nsp) 10 (PDB ID: 6W4H, resolution: $1.80 \AA$ ), (iii) RNA-dependent RNA polymerase (PDB ID: 7BV2, resolution: $2.50 \AA$ ), and (iv) SARS-CoV-2 helicase (PDB ID: 5RMM, resolution: $2.20 \AA$ ).

Redocking of the cocrystallized ligands (PRD_002214, SAM, F86, and VXG) against the active pockets of COVID19 main protease, NSP10, RNA-dependent RNA polymerase, and SARS-CoV-2 helicase, respectively, has been preceded to validate the docking procedure. The calculated RMSD values between the redocked poses and the cocrystallized were $3.10,1.07,1.34$, and 1.17 indicating the efficiency and validity of the docking processes (Figure 4).

Comprehensive docking studies were carried out using MOE14.0 software and showed generally low binding energies for compound (1) (Table 3).

Compound (1) showed good binding affinities with COVID-19 main protease $(\Delta \mathrm{G}=-21.65 \mathrm{kcal} / \mathrm{mol}), \mathrm{nsp} 10$ ( $\Delta \mathrm{G}=-20.05 \mathrm{kcal} / \mathrm{mol})$, RNA-dependent RNA polymerase $(\Delta \mathrm{G}=-28.93 \mathrm{kcal} / \mathrm{mol})$, and SARS-CoV-2 helicase ( $\Delta \mathrm{G}=-21.73 \mathrm{kcal} / \mathrm{mol}$ ), compared to the cocrystallized ligands PRD_002214 $(\Delta \mathrm{G}=-23.75 \mathrm{kcal} / \mathrm{mol}), \quad \mathrm{SAM}$ $(\Delta \mathrm{G}=-17.65 \mathrm{kcal} / \mathrm{mol}), \mathrm{F} 86(\Delta \mathrm{G}=-23.57 \mathrm{kcal} / \mathrm{mol})$, and VXG $(\Delta \mathrm{G}=-15.30 \mathrm{kcal} / \mathrm{mol})$, respectively (Table 3$)$.

Concerning the binding mode of (PRD_002214), an irreversible peptide-like inhibitor, against the COVID-19 main protease, PRD_002214 made four hydrogen bonds besides three hydrophobic interactions. The 2-oxopyrrolidin-3-yl moiety of PRD_002214 occupied the protein's first pocket. Furthermore, the isopropyl moiety was incorporated in the second pocket. Similarly, the benzyl acetate moiety occupied the third pocket of the protein. Moreover, the 5- methylisoxazole-3-carboxamide moiety occupied the fourth pocket (Figure 5).

Three hydrogen bonds and seven hydrophobic interactions had been showed by looking at the binding mode of the cocrystallized ligand (SAM) against COVID-19 nsp10. The $9 \mathrm{H}-$ purin-6-amine moiety was incorporated in three hydrophobic interactions with Phe6947 and Leu6898. The tetrahydrofuran3,4-diol moiety formed three hydrogen bonds with Asn6899, Tyr6930, and Asp6928. The (S)-(3-amino-3-carboxypropyl) dimethylsulfonium moiety formed two hydrophobic interactions, three electrostatic bonds, and one hydrogen bond with Asp6897, Lys6968, Lys6844, and Asp6928 (Figure 6).

With regards to the binding mode of the cocrystallized ligand (F86) against COVID-19 RNA-dependent RNA polymerase, F86 exhibited three hydrogen bonds in addition to six hydrophobic interactions and two electrostatic interactions. Also, it formed one hydrogen bond with Urd10. The pyrrolo [2,1-f] $[1,2,4]$ triazin-4-amine moiety formed six hydrophobic interactions with Urd20, Ade11, Arg555, and Val557. The sugar moiety formed one hydrogen bond with Asp623. The phosphate derivative moiety formed two electrostatic interactions and one hydrogen bond with Asp760, Asp623, and Cys622 (Figure 7).

Regarding the binding mode of the cocrystallized ligand (VXG) against SARS-CoV-2 helicase, VXG occupied the protein forming four hydrogen bonds besides two hydrophobic interactions. The (S)-1-acetylpyrrolidine-3-carboxylic acid moiety made four hydrogen bonds with Asn177, Asn516, and Ser486. Also, it was incorporated in two hydrophobic interactions with Tyr515 and His554 (Figure 8).

Compound (1) exhibited an interesting binding mode like that of the cocrystallized ligand against the enzymes COVID-19 main protease, nucleocapsid phosphoprotein, membrane glycoprotein, and nsp10. It occupied three pockets of COVID-19 main protease. The sugar moiety formed five hydrogen bonds with Cys145, His163, Lue141, Glu166, and Asn142. Furthermore, the lactone moiety formed two hydrophobic interactions with His41 and Met165 (Figure 9).

Concerning the binding mode of compound (1) against NSP10, the sugar moiety formed four hydrogen bonds with Gly6869, Asn6841, Asp6928, and Gly6871. Besides, the lactone moiety formed three hydrophobic interactions with Lue6898 and Met6929 (Figure 10).

For the binding mode of compound (1) against RNAdependent RNA polymerase, the sugar moiety formed four hydrogen bonds with Asp623, Ser759, Arg555, and Urd11. Besides, the lactone moiety formed six hydrophobic interactions with Urd11, Urd20, Ade11, and Val557 (Figure 11).

Regarding the binding mode of compound (1) against SARS-CoV-2 helicase, the sugar moiety formed five hydrogen bonds with Arg178, Glu201, Asn516, and Asn179. Besides, the lactone moiety formed four hydrophobic interactions with Tyr515 and His554 (Figure 12).

3.2.3. ADMET. Following the exciting results obtained from the docking studies and the fact that ADMET studies are a fundamental factor in drug discovery, we decided to carry 


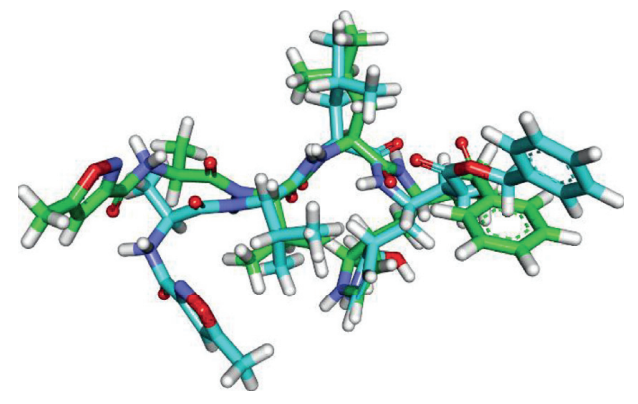

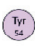

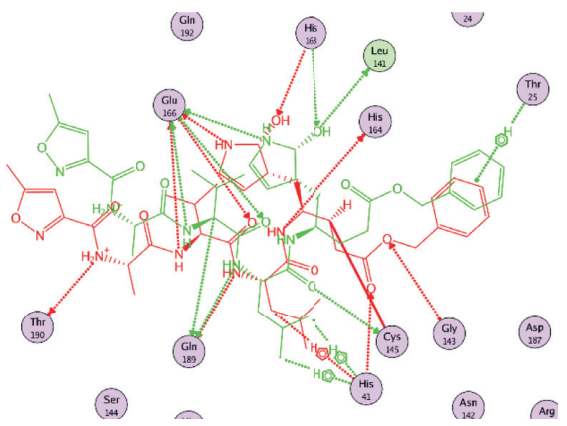

(a)

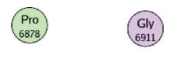
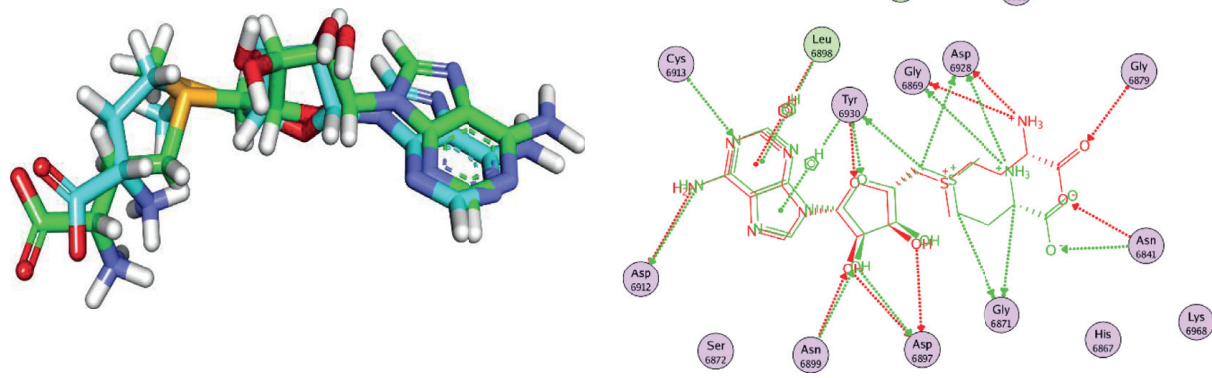

(b)
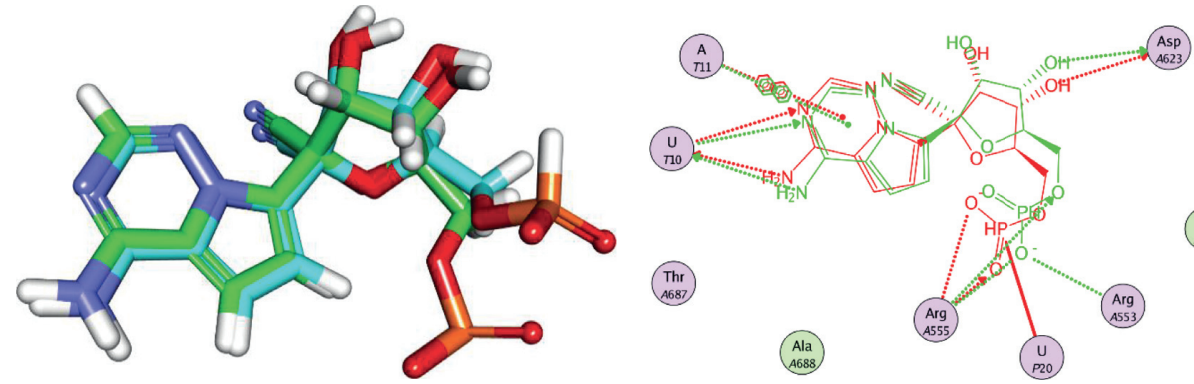

Val

(c)
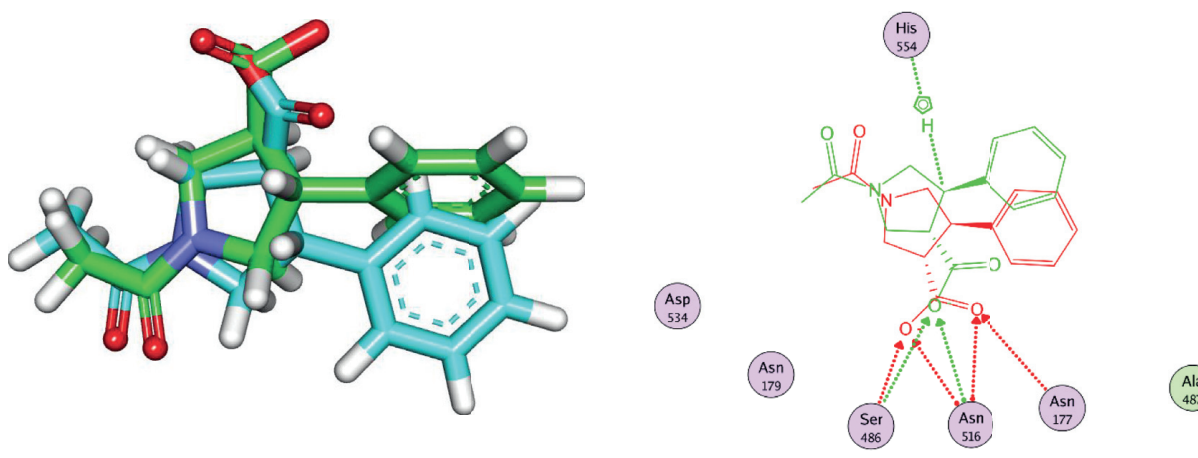

Ala

(d)

FIgURE 4: Superimposition of the cocrystallized pose and the docking pose of the same ligands. (a) PRD_002214 of COVID-19 main protease, (b) SAM of NSP10, (c) F86 of RNA-dependent RNA polymerase, and (d) VXG of SARS-CoV-2 helicase.

TABLE 3: The docking binding free energies of compound (1) and the cocrystallized ligands against SARS-CoV-2 target proteins.

\begin{tabular}{lcccc}
\hline Comp. & COVID-19 main protease & NSP10 & RNA-dependent RNA polymerase & SARS-CoV-2 helicase \\
\hline Humulene-glucoside (1) & -21.65 & -20.05 & -28.93 & -21.73 \\
Cocrystallized ligand (PRD_002214) & -23.75 & - & - & - \\
Cocrystallized ligand (SAM) & - & -17.65 & - & - \\
Cocrystallized ligand (F86) & - & - & -23.57 & - \\
Cocrystallized ligand (VXG) & - & - & -15.30 \\
\hline
\end{tabular}




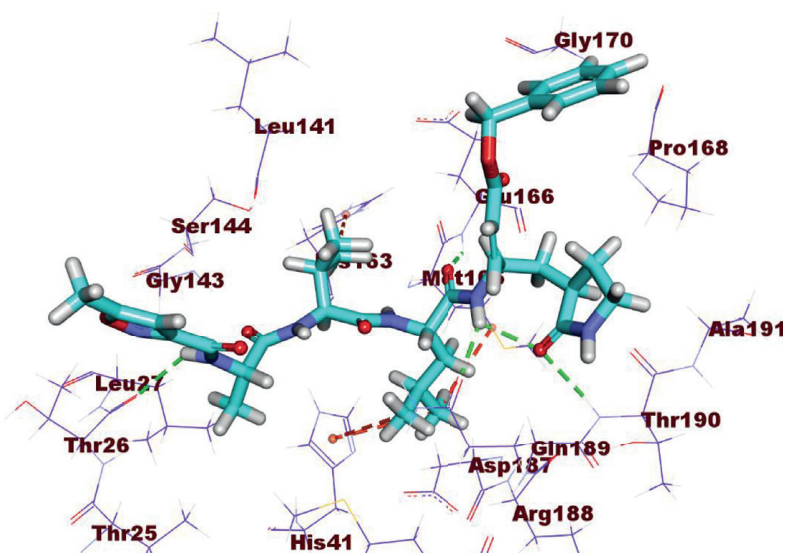

(a)

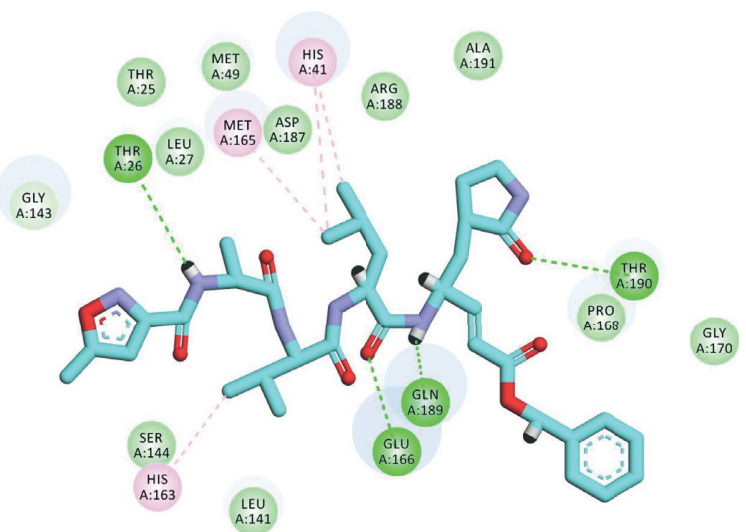

(b)

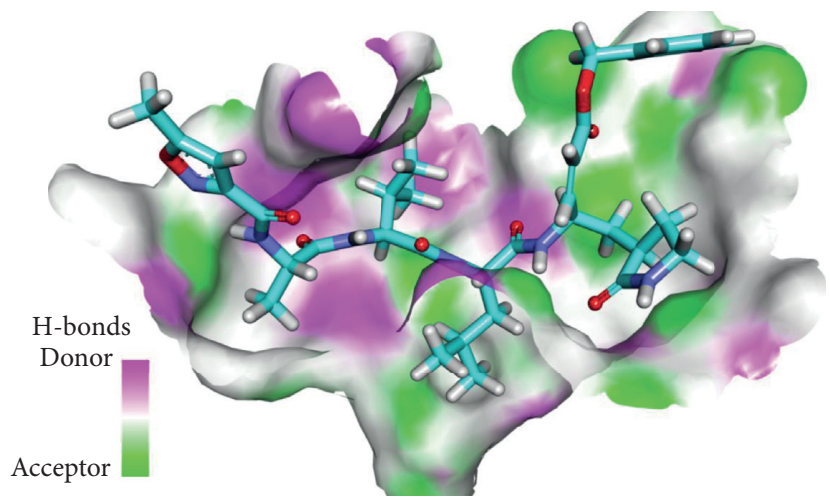

(c)

FIGURE 5: (a) 3D view of the cocrystallized ligand (PRD_002214) docked into the active site of COVID-19 main protease. (b) 2D view of PRD_002214 docked into the active site of COVID-19 main protease. (c) Mapping surface showing PRD_002214 occupying the active pocket of COVID-19 main protease.

out in silico ADMET studies. The studies were carried out on humulene-glucoside (1) using simeprevir as a reference drug. The parameters investigated with the ADMET studies included the following descriptors: (i) blood-brain barrier penetration, (ii) intestinal absorption, (iii) aqueous solubility, (iv) CYP2D6 binding, (v) hepatotoxicity prediction, and (vi) plasma protein binding. The predicted descriptors are listed in Table 4.

The results revealed that humulene-glucoside (1) has a very low $\mathrm{BBB}$ penetration level. Accordingly, the compound may be assumed to have a high degree of CNS safety.

Compound (1) showed an adequate level of ADMET aqueous solubility and intestinal absorption levels compared to simeprevir. As such, intestinal absorption of humuleneglucoside (1) could be significant.

Compound (1) was also predicted to be a noninhibitor of CYP2D6 and nonhepatotoxic. Consequently, the liver dysfunction effect is not expected to happen upon administration of humulene-glucoside (1). Regarding the plasma protein binding study, it was revealed that humulene-glucoside (1) could bind to plasma protein ${ }^{<} 90 \%$ (Figure 13).

3.2.4. Toxicity. Toxicity prediction was carried out for humulene-glucoside (1) based on Discovery Studio software
[54, 55] as follows: (i) FDA rodent carcinogenicity, (ii) carcinogenic potency $\mathrm{TD}_{50}$, (iii) rat maximum tolerated dose, (iv) rat oral $\mathrm{LD}_{50}$, (v) and rat chronic LOAEL (lowest observed adverse effect level).

As shown in Table 5, compound (1) exhibited in silico low adverse effect and toxicity against the tested models. Humulene-glucoside (1) did not show any carcinogenic tendencies in the FDA rodent carcinogenicity model and showed a $\mathrm{TD}_{50}$ value of $1.968 \mathrm{mg} / \mathrm{kg}$ body weight/day, higher than that of the reference drug simeprevir $(0.280 \mathrm{mg} /$ $\mathrm{kg}$ body weight/day).

Humulene-glucoside (1) showed a maximum tolerated dose of $0.114761 \mathrm{~g} / \mathrm{kg}$ body weight higher than simeprevir $(0.002967 \mathrm{~g} / \mathrm{kg}$ body weight $)$ and showed an oral $\mathrm{LD}_{50}$ value of $0.621649 \mathrm{mg} / \mathrm{kg}$ body weight/day. This value was higher than that of simeprevir $(0.208835 \mathrm{mg} / \mathrm{kg}$ body weight/day).

Humulene-glucoside (1) showed an LOAEL value of $0.00643343 \mathrm{~g} / \mathrm{kg}$ body weight, which was higher than that of simeprevir (00.00210575 g/kg body weight).

3.3. Biological Activities. The humulene-glucoside (1) was tested against transformed human monocytic (THP1) cells and showed no cytotoxic effect against THP1. This result agreed with the experimental in silico toxicity properties. On 


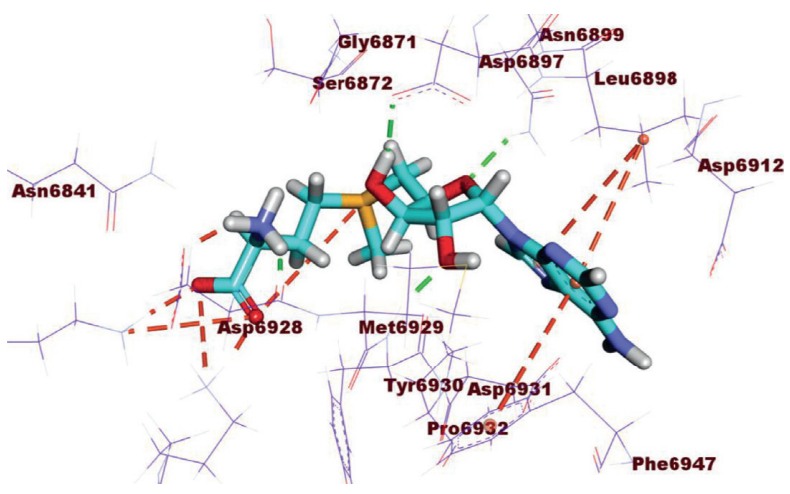

(a)

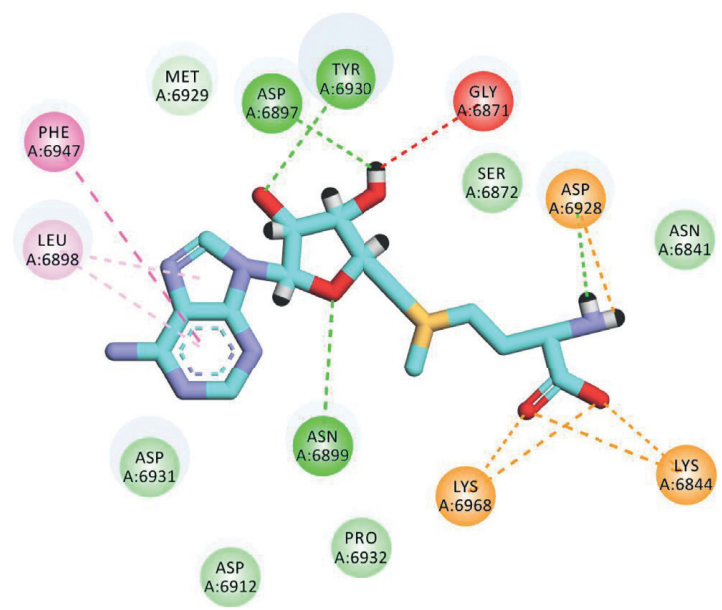

(b)

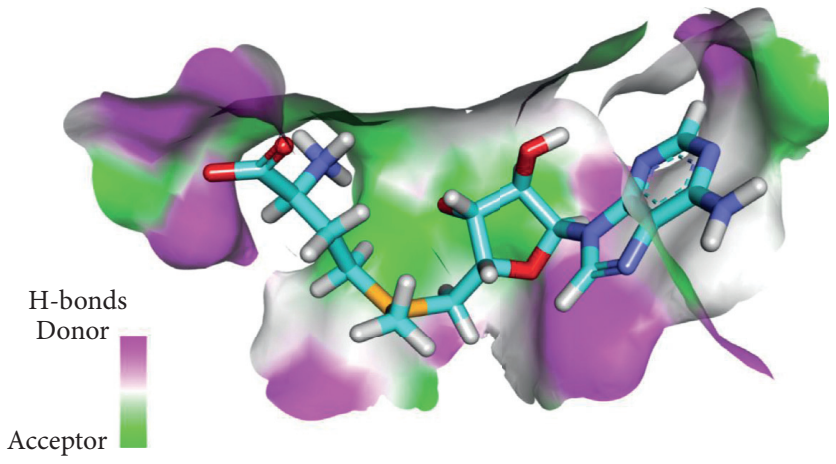

(c)

FIGURE 6: (a) 3D view of the cocrystallized ligand (SAM) docked into the active site of COVID-19 NSP10. (b) 2D view of SAM docked inside the active site of COVID-19 NSP10. (c) Mapping surface of SAM occupying the active pocket of COVID-19 NSP10.

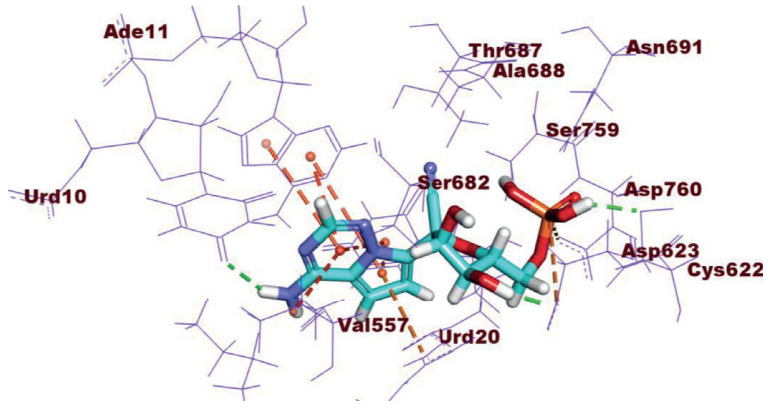

(a)

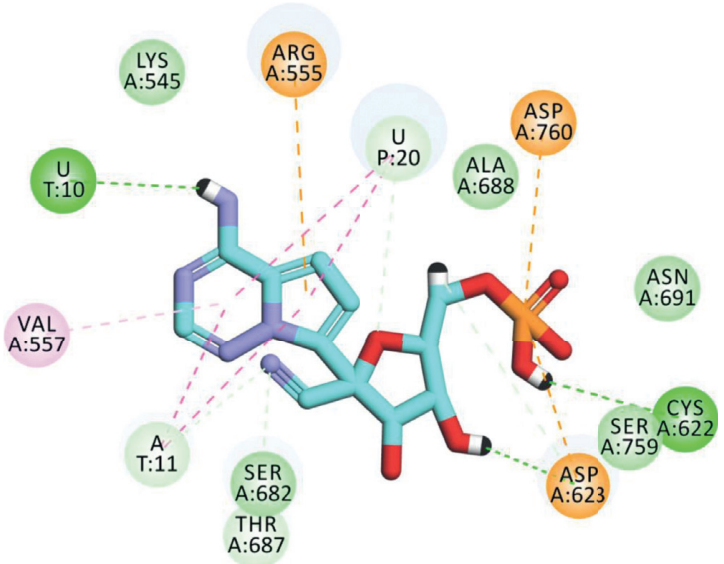

(b)

Figure 7: Continued. 


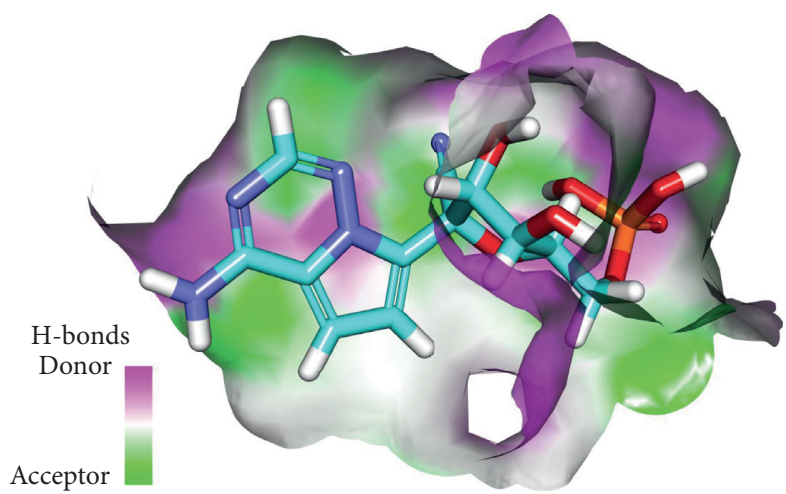

(c)

FiguRE 7: (a) 3D view of the cocrystallized ligand (F86) docked inside the active site of COVID-19 RNA-dependent RNA polymerase. (b) 2D view of F86 docked into the same active site. (c) Mapping surface of F86 occupying the active pocket of COVID-19 RNA-dependent RNA polymerase.

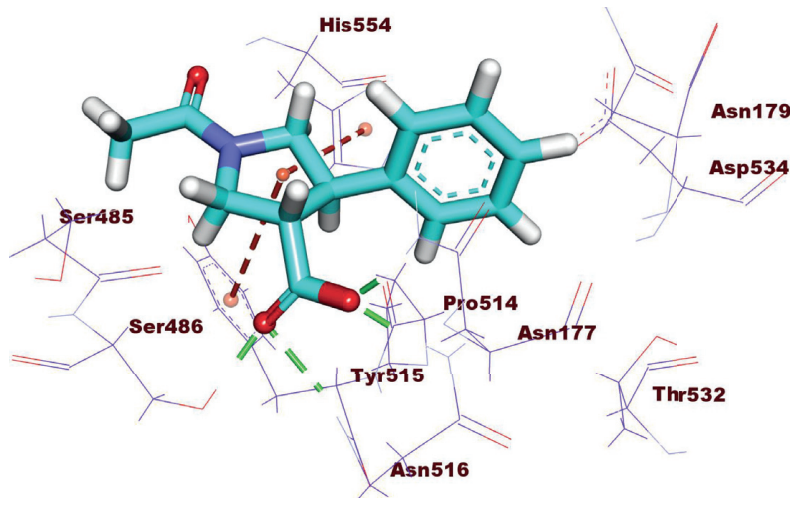

(a)

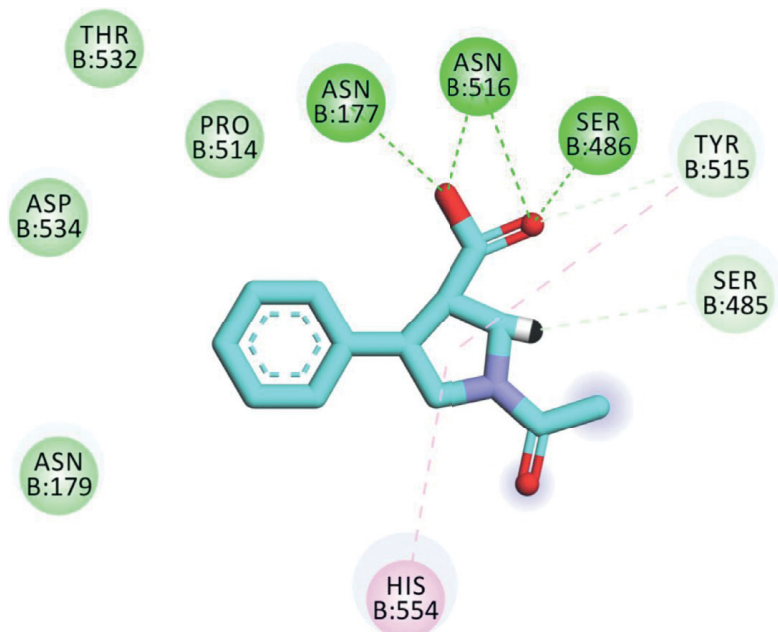

(b)

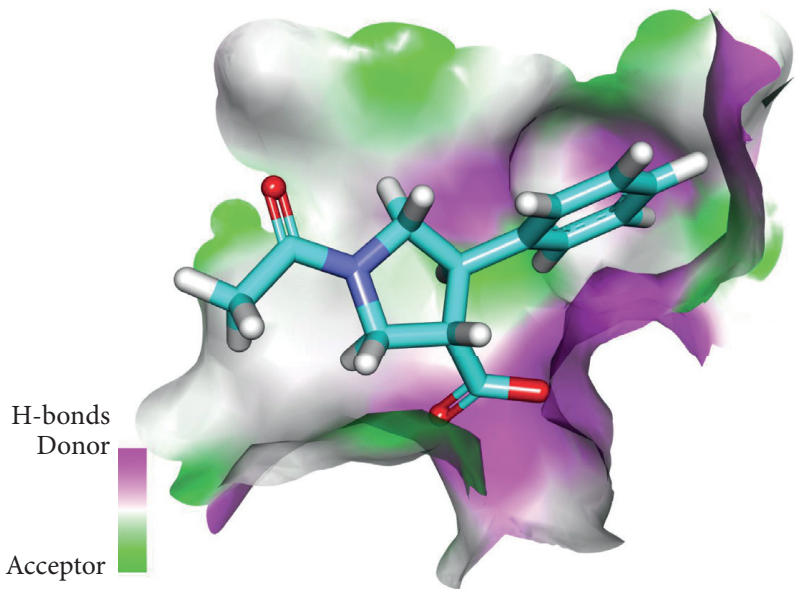

(c)

FIGURE 8: (a) 3D view of the cocrystallized ligand (VXG) docked inside the active site of SARS-CoV-2 helicase. (b) 2D view of VXG docked into the same active site. (c) Mapping surface of VXG occupying the active pocket of SARS-CoV-2 helicase. 

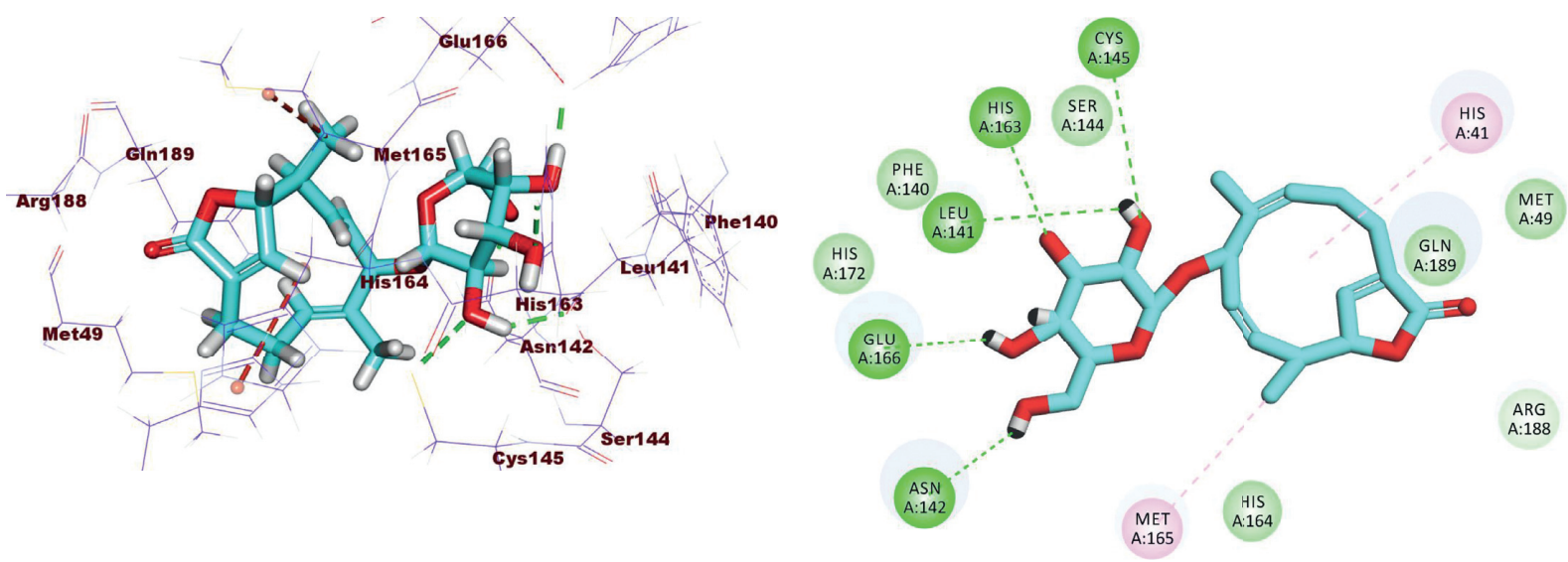

(a)

(b)

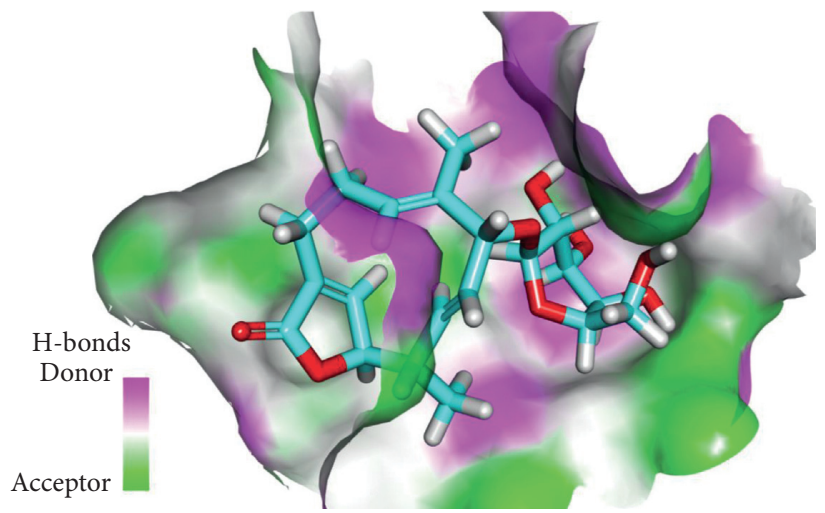

(c)

FIGURE 9: (a) 3D view of compound (1) docked in the active site of COVID-19 main protease. (b) 2D view of (1) docked into the same active site. (c) Mapping surface of (1) occupying the active pocket of COVID-19 main protease.

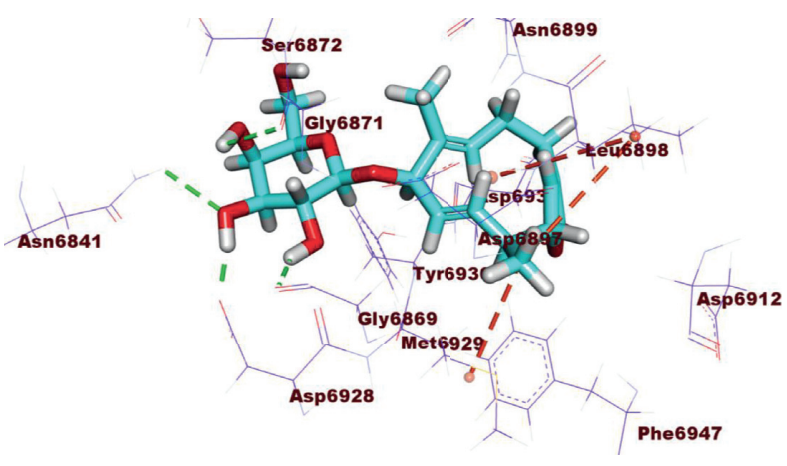

(a)

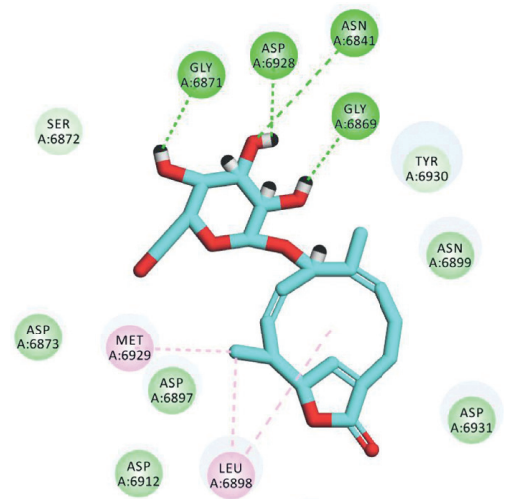

PHE

(b)

Figure 10: Continued. 


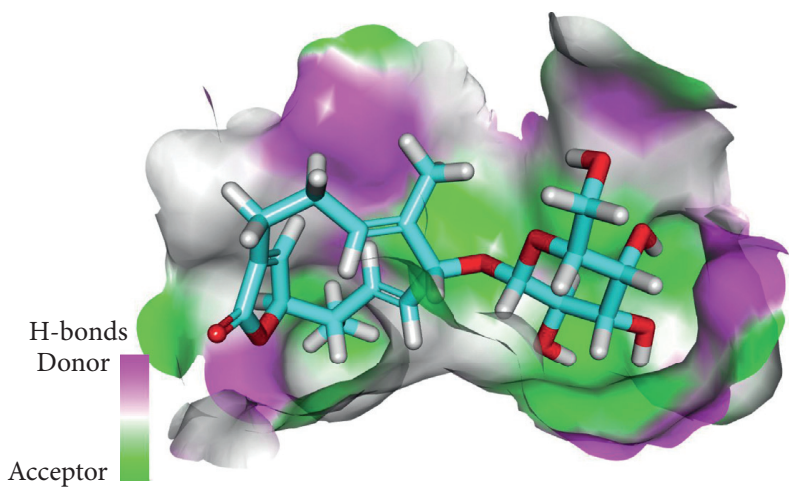

(c)

FIGURE 10: (a) 3D view of compound (1) docked in the active site of COVID-19 NSP10. (b) 2D view of compound (1) docked into the same active site. (c) Mapping surface of compound (1) occupying the active pocket of COVID-19 NSP10.

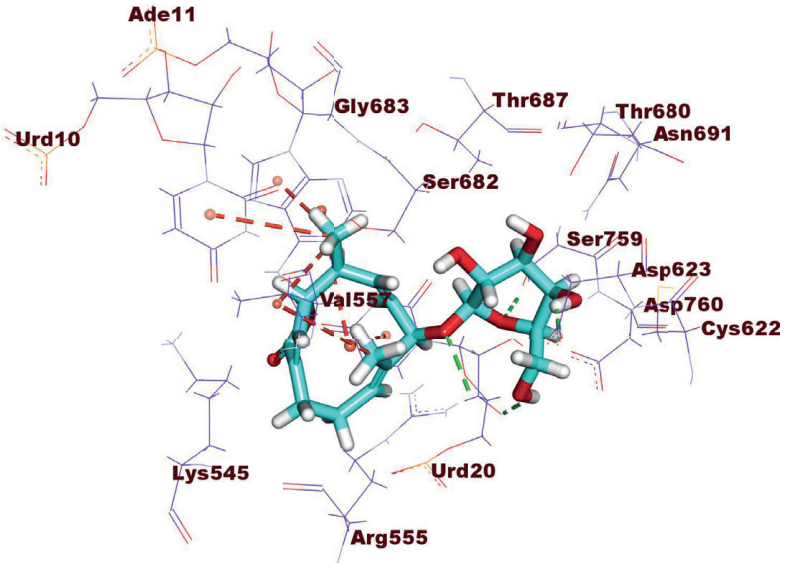

(a)

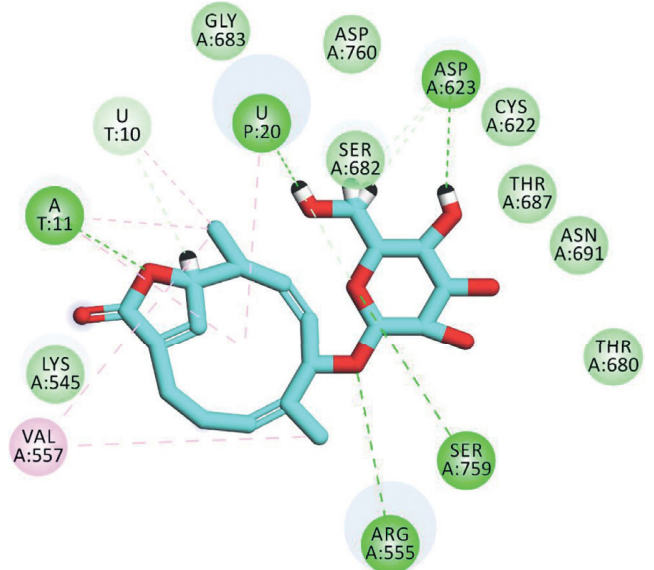

(b)

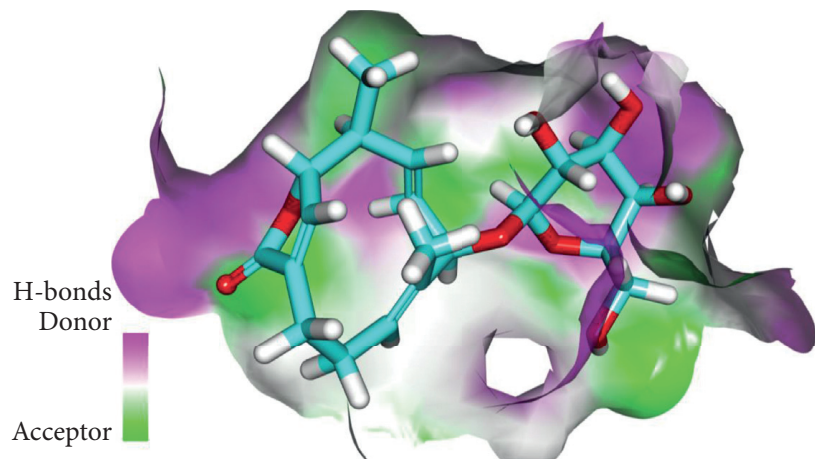

(c)

Figure 11: (a) 3D view of compound (1) docked in the active site of COVID-19 RNA-dependent RNA polymerase. (b) 2D view of compound (1) docked into the same active site. (c) Mapping surface of compound (1) occupying the active pocket of COVID-19 RNAdependent RNA polymerase. 

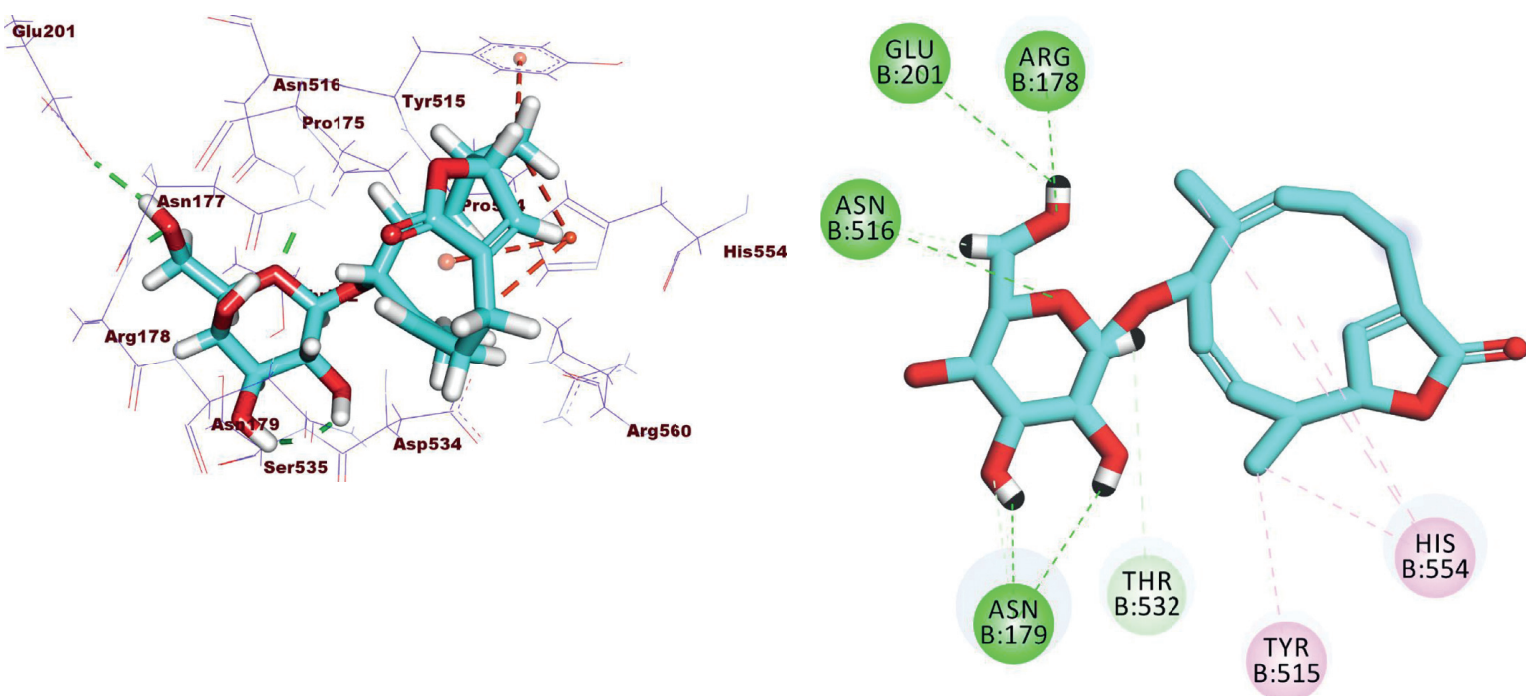

(a)

(b)

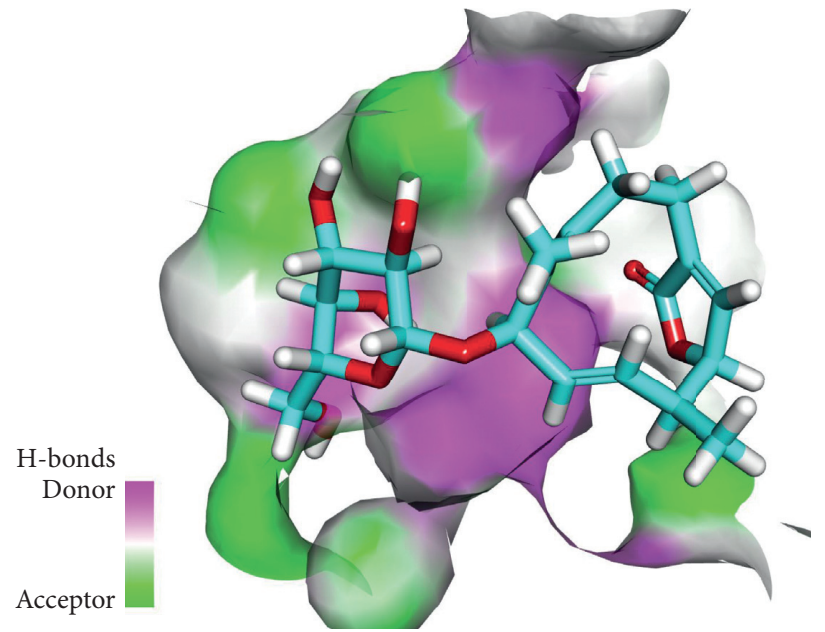

(c)

Figure 12: (a) 3D view of compound (1) docked in the active site of SARS-CoV-2 helicase. (b) 2D view of compound (1) docked into the same active site. (c) Mapping surface of compound (1) occupying the active pocket of SARS-CoV-2 helicase.

TABle 4: Predicted ADMET indices for humulene-glucoside (1) and simeprevir.

\begin{tabular}{|c|c|c|c|c|c|c|}
\hline Comp. & BBB penetration $^{\mathrm{a}}$ & Aqueous solubility level $^{\mathrm{b}}$ & Intestinal absorption level $^{c}$ & CYP2D6 inhibition $^{\mathrm{d}}$ & Hepatotoxicity $^{\mathrm{e}}$ & PPB level ${ }^{\mathrm{f}}$ \\
\hline (1) & 4 & 3 & 0 & False & False & False \\
\hline Simeprevir & 4 & 2 & 3 & False & True & True \\
\hline
\end{tabular}

${ }^{\mathrm{a}} \mathrm{BBB}$ level, the ability to penetrate the $\mathrm{BBB}, 0=$ very high, $1=$ high, $2=$ medium, $3=$ low, $4=$ very low. ${ }^{\mathrm{b}}$ Aqueous solubility level, $1=$ very low, $2=$ low, $3=$ good, $4=$ optimal. ${ }^{\mathrm{C}}$ Intestinal absorption level, $0=$ good, $1=$ moderate, $2=$ poor, $3=$ very poor. ${ }^{\mathrm{d}}$ CYP2D6, inhibition of cytochrome P2D6, TRUE=inhibitor, FALSE $=$ non inhibitor. ${ }^{\mathrm{e}} \mathrm{Hepatotoxicity,} \mathrm{TRUE}=$ hepatotoxic, FALSE = nonhepatotoxic. ${ }^{\mathrm{f}} \mathrm{PBB}$, plasma protein binding, FALSE means less than $90 \%$, TRUE means more than $90 \%$. 


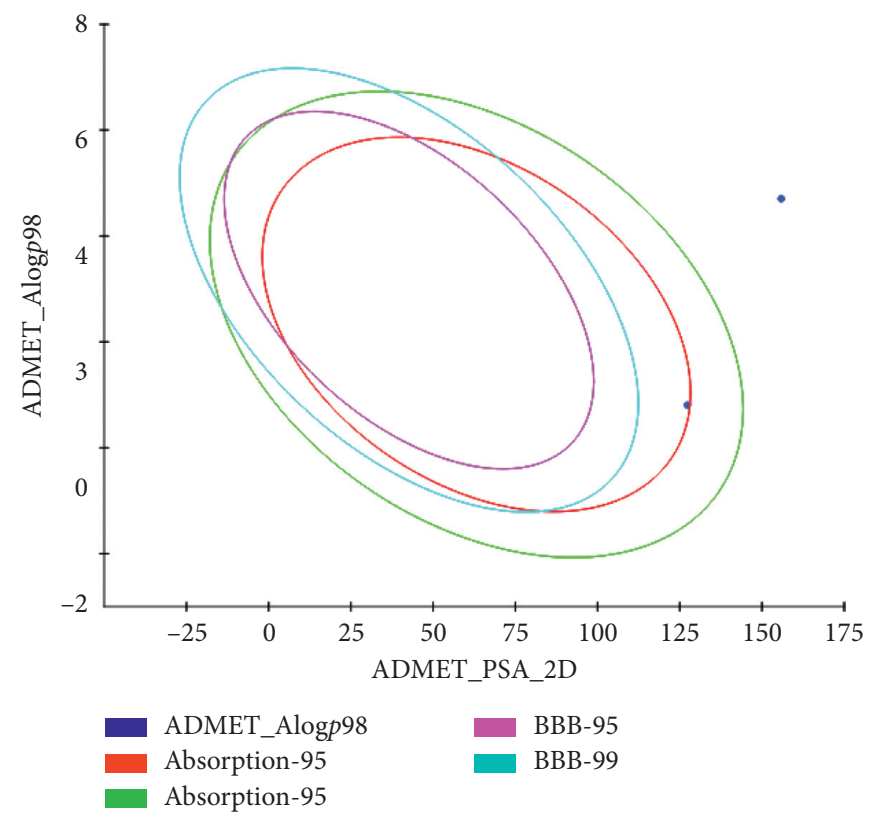

Figure 13: The expected ADMET study.

TABLE 5: In silico toxicity properties of humulene-glucoside (1).

\begin{tabular}{lccccc}
\hline Comp. & $\begin{array}{c}\text { FDA rodent } \\
\text { carcinogenicity }\end{array}$ & $\begin{array}{c}\text { TD50 rat (mg/kg body } \\
\text { weight/day) }\end{array}$ & $\begin{array}{c}\text { Rat maximum tolerated } \\
\text { dose (feed) } \\
\text { (g/kg body weight) }\end{array}$ & $\begin{array}{c}\text { Rat oral LD } \\
\text { (g/kg body weight) }\end{array}$ & $\begin{array}{c}\text { Rat chronic LOAEL } \\
\text { (g/kg body weight) }\end{array}$ \\
\hline $\mathbf{( 1 )}$ & Noncarcinogenic & 1.96797 & 0.114761 & 0.621649 & 0.00643343 \\
Simeprevir & Noncarcinogenic & 0.280349 & 0.002967 & 0.208835 & 0.00210575 \\
\hline
\end{tabular}

the other hand, compound (1) did not show promising activity against all $L$. donovani strains and both $P$. falciparum D6 and W2 clones.

\section{Conclusions}

A new humulene glucoside (1) was isolated from the methanolic extract of the whole plant of Asteriscus hierochunticus and identified to be (-)-(2Z,6E,9E) $8 \alpha$ hydroxy-2,6,9-humulatrien-1(12)-olide. Compound (1) exhibited promising in silico anti-SARS-CoV-2 activities through the binding with COVID-19 main protease $\left(\mathrm{M}^{\text {pro }}\right)$ (PDB ID: 6lu7), nonstructural protein (nsp10) (PDB ID: 6W4H), RNA-dependent RNA polymerase (PDB ID: 7BV2), and SARS-CoV-2 helicase (PDB ID: $5 \mathrm{RMM})$ with affinity values $(\Delta \mathrm{G})$ of $-21.65,-20.05$, -28.93 , and $-21.73 \mathrm{kcal} / \mathrm{mol}$, respectively. The likeness of humulene-glucoside (1) to be a drug was expected through in vitro cytotoxicity, in silico ADMET, and toxicity studies.

\section{Data Availability}

Details of the experimental part and NMR charts of compound 1 are available on request.

\section{Conflicts of Interest}

The authors declare no conflicts of interest.

\section{Acknowledgments}

This work was supported partially by USAID/HED grant 153 - 6200BF A15 - 01. The authors also acknowledge the University of Benin as a shared cost partner in this grant. Finally, the authors would like to thank the National Center for Natural Product Research (NCNPR), School of Pharmacy, University of Mississippi, for the use of their laboratory.

\section{Supplementary Materials}

S.1. Materials and Methods. Figure S1: the 1H-NMR (500 MHz, CD3OD) spectrum of 1. Figure S2: the 13C-NMR (125 MHz, CD3OD) spectrum of 1. Figure S3: the DEPT90 and $135(125 \mathrm{MHz}, \mathrm{CD} 3 \mathrm{OD})$ spectrum of 1. Figure S4: the HMQC spectrum of 1. Figure S5: the HMBC spectrum of 1. Figure S6: the $1 \mathrm{H}-1 \mathrm{H}$ cosy $(500 \mathrm{MHz}, \mathrm{CD} 3 \mathrm{OD})$ spectrum of 1. (Supplementary Materials)

\section{References}

[1] I. Steffens, "A hundred days into the coronavirus disease (COVID-19) pandemic," Eurosurveillance, vol. 25, no. 14, Article ID 2000550, 2020.

[2] WHO, WHO Coronavirus Disease (COVID-19) Dashboard, WHO, Geneva, Switzerland, 2021.

[3] G. Li and E. De Clercq, "Therapeutic options for the 2019 novel coronavirus (2019-nCoV)," Nature Reviews Drug Discovery, vol. 19, no. 3, pp. 149-150, 2020. 
[4] N. Zhong, B. Zheng, Y. Li et al., "Epidemiology and cause of severe acute respiratory syndrome (SARS) in Guangdong, People's Republic of China, in February, 2003," The Lancet, vol. 362, pp. 1353-1358, 2003.

[5] R. J. de Groot, S. C. Baker, R. S. Baric et al., "Commentary: middle east respiratory syndrome coronavirus (mers-cov): announcement of the coronavirus study group," Journal of Virology, vol. 87, pp. 7790-7792, 2013.

[6] A. M. Metwaly, M. M. Ghoneim, I. H. Eissa et al., "Traditional ancient Egyptian medicine: a review," Saudi Journal of Biological Sciences, 2021, In press.

[7] X. Han, Y. Yang, A. M. Metwaly, Y. Xue, Y. Shi, and D. Dou, "The Chinese herbal formulae (yitangkang) exerts an antidiabetic effect through the regulation of substance metabolism and energy metabolism in type 2 diabetic rats," Journal of Ethnopharmacology, vol. 239, Article ID 111942, 2019.

[8] A. L. Harvey, "Natural products in drug discovery," Drug Discovery Today, vol. 13, pp. 894-901, 2008.

[9] A. M. Metwaly, Z. Lianlian, H. Luqi, and D. Deqiang, "Black ginseng and its saponins: preparation, phytochemistry and pharmacological effects," Molecules, vol. 24, p. 1856, 2019.

[10] Y.-M. Wang, X.-K. Ran, M. Riaz et al., "Chemical constituents of stems and leaves of tagetespatula L. and its fingerprint," Molecules, vol. 24, p. 3911, 2019.

[11] A. M. Metwaly, A. S. Wanas, M. M. Radwan, S. A. Ross, and M. A. ElSohly, "New $\alpha$-pyrone derivatives from the endophytic fungus Embellisia sp," Medicinal Chemistry Research, vol. 26, pp. 1796-1800, 2017.

[12] A. Metwaly, H. Kadry, A. El-Hela, A. Elsalam, and S. Ross, "New antimalarial benzopyran derivatives from the endophytic fungus alternaria phragmospora," Planta Medica, vol. 80, 2014.

[13] A. Metwaly, "Comparative biological evaluation of four endophytic fungi isolated from nigella sativa seeds," Al-Azhar Journal of Pharmaceutical Sciences, vol. 59, pp. 123-136, 2019.

[14] A. M. Yassin, N. M. El-Deeb, A. M. Metwaly, G. F. El Fawal, M. M. Radwan, and E. E. Hafez, "Induction of apoptosis in human cancer cells through extrinsic and intrinsic pathways by balanites aegyptiaca furostanol saponins and saponincoated silvernanoparticles," Applied Biochemistry and Biotechnology, vol. 182, pp. 1675-1693, 2017.

[15] M. H. Sharaf, G. M. El-Sherbiny, S. A. Moghannem et al., "New combination approaches to combat methicillin-resistant Staphylococcus aureus (MRSA)," Scientific Reports, vol. 11, pp. 1-16, 2021.

[16] A. M. Metwaly, M. M. Ghoneim, and A. Musa, "Two new antileishmanial diketopiperazine alkaloids from the endophytic fungus Trichosporum sp," Derpharmachemica, vol. 7, pp. 322-327, 2015.

[17] A. M. Metwaly, F. R. Fronczek, G. Ma et al., “Antileukemic $\alpha$-pyrone derivatives from the endophytic fungus alternaria phragmospora," Tetrahedron Letters, vol. 55, pp. 3478-3481, 2014.

[18] A. M. Metwaly, H. A. Kadry, A. Atef et al., "Nigrosphaerin a a new isochromene derivative from the endophytic fungus Nigrospora sphaerica," Phytochemistry Letters, vol. 7, pp. 1-5, 2014.

[19] R. I. Jalmakhanbetova, Y. M. Suleimen, M. Oyama et al., "Isolation and in silico anti-COVID-19 main protease (Mpro) activities of flavonoids and a sesquiterpene lactone from artemisia sublessingiana," Journal of Chemistry, vol. 2021, Article ID 5547013, 8 pages, 2021.

[20] M. M. Ghoneim, W. M. Afifi, M. Ibrahim et al., "Biological evaluation and molecular docking study of metabolites from
Salvadora persica L. growing in Egypt," Pharmacognosy Magazine, vol. 15, no. 61, p. 232, 2019.

[21] A. Zhanzhaxina, Y. Suleimen, A. M. Metwaly et al., "In vitro and in silico cytotoxic and antibacterial activities of a diterpene from cousinia alata schrenk," Journal of Chemistry, vol. 2021, Article ID 5542455, 11 pages, 2021.

[22] D. Chaturvedi, "Sesquiterpene lactones: structural diversity and their biological activities," in Opportunity, Challenges and Scope of Natural Products in Medicinal Chemistry, pp. 313-334, Research Signpost, Thiruvananthapuram, India, 2011.

[23] R. Jalmakhanbetova, E. B. Elkaeed, I. H. Eissa, A. M. Metwaly, and Y. M. Suleimen, "Synthesis and molecular docking of some grossgemin amino derivatives as tubulin inhibitors targeting colchicine binding site," Journal of Chemistry, vol. 2021, Article ID 5586515, 10 pages, 2021.

[24] V. A. Funk, R. J. Bayer, S. Keeley et al., "Everywhere but Antarctica: using a supertree to understand the diversity and distribution of the compositae," Biologiske Skrifter, vol. 55, pp. 343-374, 2005.

[25] R. Messaoudi, A. Cheriti, and Y. Bourmita, "Bioassay-guided isolation of the major compound with antioxidant activity from the algerian medicinal plant bubonium graveolens," Asian Journal of Pharmaceutical and Clinical Research, vol. 11, pp. 424-426, 2018.

[26] J. I. Achika, D. E. Arthur, I. Gerald, and A. Adedayo, "A review on the phytoconstituents and related medicinal properties of plants in the asteraceae family," International Organization of Scientific Research Journal of Applied Chemistry, vol. 7, pp. 1-8, 2014.

[27] A. San Feliciano, A. Barrero, J. M. del Corral, E. Ledesma, and F Sánchez-Ferrando, A. Asteriscunolide, Humulanolide from asteriscus aquaticus," Tetrahedron Letters, vol. 23, pp. 30973100, 1982.

[28] A. San Feliciano, A. Barrero, M. Medarde, J. M. del Corral, A. A. Aizpiri, and F. Sánchez-Ferrando, "Asteriscunolides A, $\mathrm{B}, \mathrm{C}$ and $\mathrm{D}$, the first humulanolides; two pairs of conformationally stable stereoisomers," Tetrahedron, vol. 40, pp. 873-878, 1984.

[29] A. San Feliciano, A. Barrero, M. Medarde et al., "A sesquiterpene lactone with a new natural skeleton," Tetrahedron Letters, vol. 26, pp. 2369-2372, 1985.

[30] R. Yazdanparast, A. Ardestani, and S. Jamshidi, "Experimental diabetes treated with Achillea santolina: effect on pancreatic oxidative parameters," Journal of Ethnopharmacology, vol. 112, pp. 13-18, 2007.

[31] B. Chengaiah, K. M. Rao, K. M. Kumar, M. Alagusundaram, and C. M. Chetty, "Medicinal importance of natural dyes-a review," International Journal of PharmTech Research, vol. 2, pp. 144-154, 2010.

[32] J. B. Althaus, M. Kaiser, R. Brun, and T. J. Schmidt, "Antiprotozoal activity of Achillea ptarmica (asteraceae) and its main alkamide constituents," Molecules, vol. 19, pp. 64286438, 2014.

[33] V. O. Imieje, A. A. Zaki, A. M. Metwaly et al., "Antileishmanial derivatives of humulene from Asteriscus hierochunticus with in silico tubulin inhibition potential," Records of Natural Products, vol. 2021, 2021.

[34] P. Labute, "LowModeMD-implicit low-mode velocity filtering applied to conformational search of macrocycles and protein loops," Journal of Chemical Information and Modeling, vol. 50, pp. 792-800, 2010.

[35] M. S. Alesawy, A. E. Abdallah, M. S. Taghour, E. B. Elkaeed, I. H. Eissa, and A. M. Metwaly, "In silico studies of some 
isoflavonoids as potential candidates against COVID-19 targeting human ACE2 (hACE2) and viral main protease (Mpro)," Molecules, vol. 26, p. 2806, 2021.

[36] A. El-Demerdash, A. M. Metwaly, A. Hassan et al., "Comprehensive virtual screening of the antiviral potentialities of marine polycyclic guanidine alkaloids against SARS-CoV-2 (COVID-19)," Biomolecules, vol. 11, p. 460, 2021.

[37] J. Mikus and D. Steverding, "A simple colorimetric method to screen drug cytotoxicity against Leishmania using the dye alamar blue ${ }^{\circledR}, "$ Parasitology International, vol. 48, pp. 265269, 2000.

[38] S. K. Jain, R. Sahu, L. A. Walker, and B. L. Tekwani, “A parasite rescue and transformation assay for antileishmanial screening against intracellular leishmania donovani amastigotes in THP1 human acute monocytic leukemia cell line," JoVE (Journal of Visualized Experiments), vol. 70, p. 4054, 2012.

[39] M. M. Hegazy, A. M. Metwaly, A. E. Mostafa et al., "Biological and chemical evaluation of some African plants belonging to kalanchoe species: antitrypanosomal, cytotoxic, antitopoisomerase I activities and chemical profiling using ultraperformance liquid chromatography/quadrupole-time-offlight mass spectrometer," Pharmacognosy Magazine, vol. 17, p. 6, 2021 .

[40] M. Makler, J. Ries, J. Williams et al., "Parasite lactate dehydrogenase as an assay for plasmodium falciparum drug sensitivity," The American Journal of Tropical Medicine and Hygiene, vol. 48, pp. 739-741, 1993.

[41] L. Hammoud, F. León, I. Brouard et al., "Humulene derivatives from saharian asteriscus graveolens," Tetrahedron Letters, vol. 59, pp. 2668-2670, 2018.

[42] A. San Feliciano, A. F. Barrero, M. Medarde et al., "The stereochemistry of asteriscunolides: an x-ray based correction," Tetrahedron, vol. 41, pp. 5711-5717, 1985.

[43] H. Lin and L. Ji-Kai, "The first humulene type sesquiterpene from Lactarius hirtipes," Zeitschrift für Naturforschung C, vol. 57, pp. 571-574, 2002.

[44] F. Zulfiqar, S. I. Khan, Z. Ali et al., "Norlignan glucosides from Hypoxis hemerocallidea and their potential in vitro anti-inflammatory activity via inhibition of iNOS and NF- $\kappa \mathrm{B}$," Phytochemistry, vol. 172, Article ID 112273, 2020.

[45] L. Zhang, D. Lin, X. Sun et al., "Crystal structure of SARSCoV-2 main protease provides a basis for design of improved $\alpha$-ketoamide inhibitors," Science, vol. 368, pp. 409-412, 2020.

[46] M. Prajapat, P. Sarma, N. Shekhar et al., "Drug targets for corona virus: a systematic review," Indian Journal of Pharmacology, vol. 52, no. 1, pp. 56-65, 2020.

[47] M. Bouvet, A. Lugari, C. C. Posthuma et al., "Coronavirus Nsp10, a critical co-factor for activation of multiple replicative enzymes," Journal of Biological Chemistry, vol. 289, pp. 25783-25796, 2014.

[48] Y. Jiang, W. Yin, and H. E. Xu, "RNA-dependent RNA polymerase: structure, mechanism, and drug discovery for COVID-19," Biochemical and Biophysical Research Communications, vol. 538, pp. 47-53, 2021.

[49] E. Jankowsky, "RNA helicases at work: binding and rearranging," Trends in Biochemical Sciences, vol. 36, pp. 19-29, 2011.

[50] N. Martins, S. Petropoulos, and I. C. Ferreira, "Chemical composition and bioactive compounds of garlic (Allium sativum L.) as affected by pre-and post-harvest conditions: a review," Food Chemistry, vol. 211, pp. 41-50, 2016.

[51] I. H. Eissa, A.-G. A. El-Helby, H. A. Mahdy et al., "Discovery of new quinazolin-4 (3H)-ones as VEGFR-2 inhibitors: design, synthesis, and anti-proliferative evaluation," Bioorganic Chemistry, vol. 105, Article ID 104380, 2020.

[52] K. El-Adl, A.-G. A. El-Helby, R. R. Ayyad et al., "Design, synthesis, and anti-proliferative evaluation of new quinazolin$4(3 \mathrm{H})$-ones as potential VEGFR-2 inhibitors," Bioorganic \& Medicinal Chemistry, vol. 29, Article ID 115872, 2021.

[53] A.-G. A. El-Helby, H. Sakr, R. R. Ayyad et al., "Design, synthesis, molecular modeling, in vivo studies and anticancer activity evaluation of new phthalazine derivatives as potential DNA intercalators and topoisomerase II inhibitors," Bioorganic Chemistry, vol. 103, Article ID 104233, 2020.

[54] X. Xia, E. G. Maliski, P. Gallant, and D. Rogers, "Classification of kinase inhibitors using a bayesian model," Journal of Medicinal Chemistry, vol. 47, pp. 4463-4470, 2004.

[55] BIOVIA, QSAR, ADMET and Predictive Toxicology, Dassault Systèmes, Vélizy-Villacoublay, France, 2020. 